\title{
Efficacy of short-term intensive treatment with insulin pump to improve islet $\beta$-cell function in newly diagnosed type 2 diabetes via inhibition of oxidative stress
}

\author{
HAI-TONG LIU* and YAN GAO* \\ Endocrine Department, Daqing Oilfield General Hospital, Daqing, Heilongjiang 163001, P.R. China
}

Received August 11,2018; Accepted April 11, 2019

DOI: $10.3892 /$ etm.2019.7821

\begin{abstract}
The present study (Chinese Trial Registry GTB7027) assessed the effects of short-term intensive treatment with insulin pump on islet cell function in patients with newly diagnosed type 2 diabetes and the possible mechanism. A total of 100 patients newly diagnosed with type 2 diabetes and hospitalized between January 2016 and December 2017 were divided into a control and an experimental group ( $\mathrm{n}=50$ in each group). The subjects of the control group were administered multiple insulin injections for intensive treatment, while the experimental group received short-term intensive treatment with an insulin pump. Analysis of blood parameters, including lipids and glucose, as well as islet $\beta$-cell function were performed. The level of reactive oxygen species (ROS) in the peripheral blood mononuclear cells (PBMCs) from the patients was also measured. Oxidative stress indicators, including serum malondialdehyde (MDA) and superoxide dismutase (SOD), were also examined to explore the possible mechanism. The mRNA expression of heme oxygenase 1 (HO-1) and nuclear factor erythroid 2-related factor 2 (Nrf2) in PBMCs were analyzed by reverse transcription-quantitative PCR. The results indicated that the blood lipid levels were significantly improved in the two groups at two weeks, while the experimental group had significantly lower levels of total cholesterol and triglyceride, as well as low- and high-density lipoprotein cholesterol. The function of islet $\beta$-cells was significantly improved in the two groups. The insulin secretion index [homeostasis model assessment (HOMA) of $\beta$-cell function] in the experimental group was higher, while the insulin resistance (IR) index (HOMA of IR) was significantly lower than that in the control group. The serum MDA level
\end{abstract}

Correspondence to: Miss Hai-Tong Liu, Endocrine Department, Daqing Oilfield General Hospital, 9 Zhongkang Street, Daqing, Heilongjiang 163001, P.R. China

E-mail: liuhaitongbio@outlook.com

${ }^{*}$ Contributed equally

Key words: type 2 diabetes, insulin pump, malondialdehyde, islet function, oxidative stress in the experimental group was significantly lower and the SOD level was significantly higher compared with that in the control group. Following treatment, the level of ROS in diabetic PBMCs was significantly reduced, and the transcription level of HO-1 and Nrf2 were also significantly reduced $(\mathrm{P}<0.05)$. These results demonstrated that short-term intensive treatment with an insulin pump significantly improved lipid and blood glucose metabolism to protect islet function as well as significantly reducing the level of oxidative stress in patients with newly diagnosed type 2 diabetes.

\section{Introduction}

Type 2 diabetes is an endocrine and metabolic disease characterized by a disturbance of the blood glucose and lipid metabolism. The cause of this disease is pancreatic $\beta$-cell dysfunction and insulin resistance $(1,2)$. Patients with newly diagnosed type 2 diabetes have impaired insulin secretion and insulin resistance. The lack of insulin secretion is mainly due to the inhibition of islet function caused by hyperglycemia (3). Hyperglycemia induces and exacerbates pancreatic $\beta$-cell damage and insulin resistance. Impaired secretion of $\beta$-cells in pancreatic islets results in oxidative stress and subsequent apoptosis. Under high-glucose conditions, the oxidative stress in pancreatic $\beta$-cells increases when a series of cytokines and reactive oxygen species (ROS) are released, triggering the activation of death signaling pathways in islet cells (4). However, early islet $\beta$-cell dysfunction is partially reversible and early intensive treatment may control blood glucose levels to protect islet $\beta$-cells to achieve the goal of improving the prognosis of patients with type 2 diabetes $(5,6)$. Programs for intensive treatment commonly include the use of insulin pumps for continuous subcutaneous infusion of insulin and short-acting pre-prandial insulin may be added as subcutaneous intermediate-acting or long-term insulin as an injection prior to bedtime.

Insulin pump therapy [continuous subcutaneous insulin infusion (CSII)] activates the physiological secretion pattern of insulin in patients with newly detected type 2 diabetes, while not affecting oral hypoglycemic agents, and which may rapidly and efficiently regulate blood glucose to the anticipated level in order to relieve high glycotoxicity and enhance the islet function of islet $\beta$-cells.

The present study examined and compared the effect of two different short-term intensive treatment schedules of insulin 
pump and numerous subcutaneous insulin injections on blood lipids, blood glucose and islet $\beta$-cell secretion in patients with newly diagnosed type 2 diabetes mellitus, and explored the possible mechanisms.

\section{Materials and methods}

General data. A total of 100 patients with newly diagnosed type 2 diabetes mellitus hospitalized at Daqing Oilfield General Hospital (Daqing, China) between January 2016 to December 2017 were selected for the present study. Patients who met the diagnostic criteria for diabetes of the World Health Organization from 1999 (7), fasting plasma glucose $>11.1 \mathrm{mmol} / \mathrm{l}$ and/or glycosylated hemoglobin (HbA1c) $\geq 9.0 \%$, never received any oral hypoglycemics, lipid-regulating drugs or insulin treatment, glutamic acid decarboxylase antibody, were negative for islet cell antibody and urinary protein, had no acute complications and no diabetic retinopathy on fundus examination were included in the present study. The exclusion criteria were as follows: Severe heart, liver or renal insufficiency or severe systemic complications, accompanied by endocrine or immune system diseases. Patients were divided into a control group and an experimental group according to the random number table method, with 50 patients in each group. In the control group, there were 28 males and 22 females aged between 40 to 57 , with an average age of $48.31 \pm 7.83$ years and a mean body mass index (BMI) of $27.20 \pm 2.67 \mathrm{~kg} / \mathrm{m}^{2}$; while the experimental group comprised 27 males and 23 females aged between 39 to 58 with an average age of $48.53 \pm 8.63$ years and the average BMI was $27.31 \pm 2.95 \mathrm{~kg} / \mathrm{m}^{2}$. There was no statistically significant difference between the two groups in terms of age, sex and other general data, indicating comparability between the two groups.

Methods. Patients in the control group were administered a subcutaneous injection of insulin $15 \mathrm{~min}$ prior to meals and insulin was given subcutaneously prior to bedtime. The specific dosage was calculated according to the patients' BMI. The daily starting dose was $0.4-0.6 \mathrm{IU} / \mathrm{kg}$, based on blood glucose levels. The dosage was adjusted according to the monitoring results, with continuous treatment for 2 weeks. The patients in the study group were treated with a Misting MTI-PII insulin pump (Milestone). The pumps were located on the subcutaneous tissue of both sides of the umbilicus, and insulin aspart was used. The specific dosage was calculated according to the patients' BMI and the daily starting dose was $0.4-0.6 \mathrm{IU} / \mathrm{kg}$. Of the daily insulin dose, $50 \%$ was administered by continuous subcutaneous injection, whilst the remaining insulin was divided into three equal portions pumped prior to meals with the dose adjusted according to blood glucose monitoring results, with continuous treatment for two weeks. The calculation of the total amount of insulin, the amount of basal and the amount of pre-loading insulin prior to meals was calculated for each patient.

Observational indicators. The patients' fasting venous blood was collected in the morning and the associated indicators were examined and compared prior to- and following 2 weeks of treatment. The blood lipid indicators of total cholesterol (TC), triglycerides (TG), low-density lipoprotein-cholesterol
(LDL-C) and high-density lipoprotein-cholesterol (HDL-C) were measured with an automatic blood biochemical analyzer (SMT-100; Perlong Medical Equipment Co., Ltd.). The general blood glucose parameters, including fasting plasma glucose (FPG), 2-h post-prandial blood glucose (2 h PG, HbAlc level, fasting C-peptide (CP) and post-prandial $2 \mathrm{~h} \mathrm{C}$-peptides (2hC-P) were detected. The insulin function index [homeostasis model assessment of insulin resistance (HOMA-IR)] and insulin secretion index [HOMA of $\beta$-cell function (HOMA- $\beta$ )] of islet cell function were calculated by using the following formula: HOMA-IR=FPGxFast Insulin/22.5, HOMA- $\beta=20 x$ Fast Insulin/(FPG-3.5). Oxidative stress markers, including malondialdehyde (MDA) and superoxide dismutase (SOD) levels, were detected by ELISA (cat. no. ab188392; Abcam).

Isolation of peripheral blood mononuclear cells (PBMCs). Venous blood $(12 \mathrm{ml})$ was collected from the patients early in the morning. PBMCs were isolated by density gradient centrifugation in a Ficoll lymphocyte separation solution within $2 \mathrm{~h}$ as follows: Anti-coagulation agent was mixed with an equal volume of PBS, and an equal volume of lymphocyte separation solution was slowly added, followed by horizontal centrifugation at $12,000 \mathrm{x} \mathrm{g}$ for $25 \mathrm{~min}$ at $37^{\circ} \mathrm{C}$. The cells in the buffy coat were aspirated and washed twice with PBS, and the PBMCs were isolated.

Dichloro-dihydro-fluorescein diacetate (DCFH-DA) assay. The ROS levels in PBMCs were detected by using a Reactive Oxygen Species ROS Detection Kit (Cell Biolabs, Inc.). The experimental procedure was according to the manufacturer's protocol. The mean fluorescence intensity (MFI) of samples was measured using a flow cytometer with an excitation wavelength of $488 \mathrm{~nm}$ and an emission wavelength of $525 \mathrm{~nm}$.

Detection of the mRNA level of heme oxygenase 1 (HO-1) and Nrf2 nuclear factor erythroid 2-related factor 2 (Nrf2). The total RNA of PBMCs was extracted by using TRIzol and the transcription levels of $\mathrm{HO}-1$ and $\mathrm{Nrf} 2$ were detected by reverse transcription (RT)-quantitative PCR. The specific primers were as follows: HO-1 forward, 5'-ATGGCCTCC CTGTACCACATc-3' and reverse, 5'-TGTTGCGCTCAA TCTCCTCCT-3'; Nrf2 forward, 5'-TGAGGTTTCTTCGGC TACGTT-3' and reverse, 5'-CTTCTGTCAGTTTGGCTT CTGG-3'; GAPDH forward, 5'-ACCAGCCTCAAGATCATC AGC-3' and reverse, 5'-TGCTAAGCAGTTGGTGGTGC-3'. GAPDH was used as an internal reference. The complementary DNA was synthesized using the PrimeScript RT reagent kit (RR037A; Takara Bio, Inc.) according to the manufacturer's protocol. qPCR was was performed using SYBRGreen (Thermo Fisher Scientific, Inc.) and the Roche Light Cycler 480 II (Roche Diagnostics Ltd.). The PCR conditions were as follows: Denaturation at $95^{\circ} \mathrm{C}$ for $5 \mathrm{~min}$, followed by 40 cycles of $95^{\circ} \mathrm{C}$ for $30 \mathrm{sec}, 58^{\circ} \mathrm{C}$ for $30 \mathrm{sec}$ and $72^{\circ} \mathrm{C}$ for $30 \mathrm{sec}$. The quantification cycle $(\mathrm{Cq})$ value was obtained from the PCR amplification curve and relative quantification was performed using the $2^{-\Delta \Delta C q}$ method (8).

Statistical methods. SPSS 17.0 statistical software (SPSS, Inc.) was used for statistical analysis of the data. The count data are presented as frequencies and percentages, while 

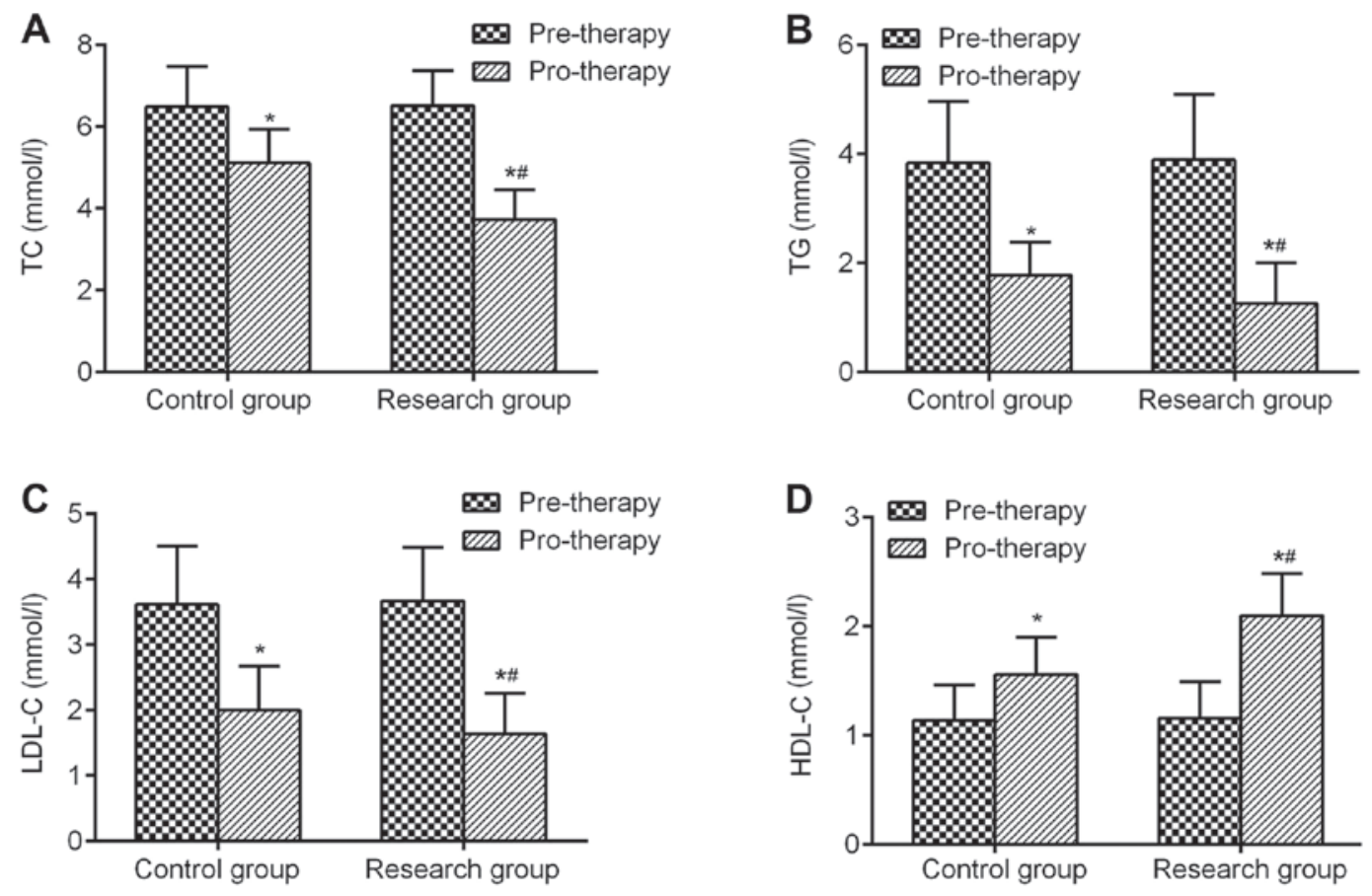

Figure 1. Short-term intensive insulin pump therapy improved blood lipid levels in patients with newly diagnosed type 2 diabetes. (A) Serum TC levels, (B) serum TG levels, (C) serum LDL-C levels and (D) serum HDL-C levels were determined pre- and pro-therapy. " $\mathrm{P}<0.05$ vs. pre-therapy; ${ }^{\#} \mathrm{P}<0.05$ vs. pro-therapy in control group. TC, total cholesterol; TG, triglycerides; LDL-C, low-density lipoprotein-cholesterol; HDL-C, high-density lipoprotein-cholesterol.

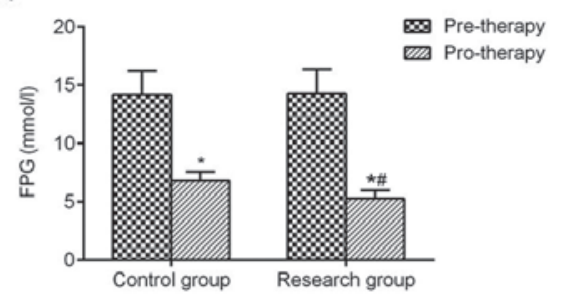

C

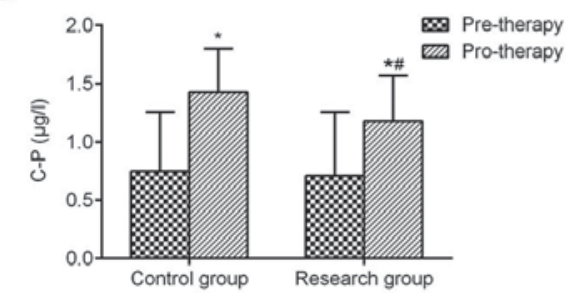

D

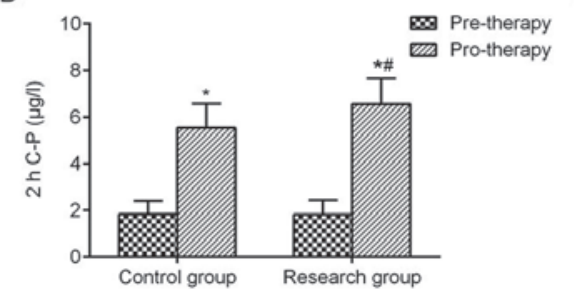

B

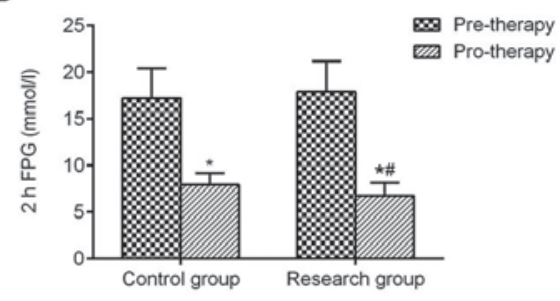

E

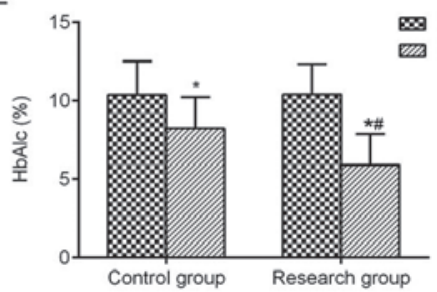

Figure 2. Short-term intensive insulin pump therapy significantly improved blood glucose levels in newly diagnosed type 2 diabetics. (A) serum FPG levels, (B) serum 2-h PG level, (C) serum CP level, (D) serum 2-h C-P level and (E) serum HbAlc level pre- or pro-therapy. ${ }^{*} \mathrm{P}<0.05$ vs. pre-therapy; ${ }^{*} \mathrm{P}<0.05$ vs. pro-therapy in control group. FPG, fasting plasma glucose; PG, post-prandial blood glucose; C-P, C-peptides; HbAlc, glycated hemoglobin.

measurement data with a normal distribution are presented as the mean \pm standard deviation analyzed by Shapiro-Wilk test. One-way analysis of variance with Tukey's post-hoc test was performed to analyze differences among multiple groups. $\mathrm{P}<0.05$ was considered to indicate statistical significance.

\section{Results}

Short-term intensive insulin pump therapy improves blood lipid levels. As blood lipid levels, serum TC, TG, LDL-C and HDL-C level were measured in the two groups. Prior to insulin treatment, the blood lipid levels of TC, TG, LDL-C and
HDL-C were similar between the two groups, with no statistically significant difference (Fig. 1). The blood lipid levels of all of the patients after intensive treatment were significantly improved. The levels of TC, TG, and LDL-C was significantly lowered in the experimental group compared with those in the control group (Fig. 1A-C), and the level of HDL-C was higher than that in the control group (Fig. 1D).

Short-term intensive insulin pump therapy improves glycemic index in patients. In order to detect blood glucose levels in the two groups, FPG, 2 hPG, C-P, 2hC-P and HbAlc were measured. Prior to treatment, the serum FPG, 2hPG, CP, 
2hC-P and HbAlc levels were similar between the two groups with no statistically significant difference (Fig. 2). Of note, the blood glucose levels in the two groups were significantly improved after intensive treatment compared with pre-therapy. The levels of FPG, 2hPG and HbAlc in the experimental group were lower compared with the control group (Fig. 2A, B and E), while the levels of $\mathrm{CP}$ and $2 \mathrm{hC}-\mathrm{P}$ were higher compared with the pre-therapy group (Fig. $2 \mathrm{C}$ and D). Furthermore, the results of pro-therapy between control group and experimental groups was of remarkable significance.

Short-term intensive insulin pump therapy improves the function of islet $\beta$-cells. To detect the function of islet $\beta$-cells in the two groups, the HOMA- $\beta$ and HOMA-IR indices were determined. Prior to treatment, there was no significant difference between the two groups regarding their HOMA- $\beta$ and HOMA-IR. After intensive treatment, the function of the islet $\beta$-cells was significantly improved in each group and the HOMA- $\beta$ in the experimental group was significantly higher than that in the control group, while the HOMA-IR was lower than that in the control group (Table I).

Short-term intensive insulin pump therapy improves oxidative stress. In order to detect redox indicators, the serum MDA and SOD levels were determined in the two groups. Prior to treatment, serum MDA and SOD levels were similar between the two groups and no significant differences were observed. After intensive treatment, the redox parameters of the two groups were significantly improved and the serum MDA levels in the experimental group were significantly lower than those of the control group. The serum SOD levels in the experimental group were significantly higher than those in the control group, as presented in Fig. 3A and B. Moreover, the results of pro-therapy between control group and experimental groups was of remarkable significance.

Short-term intensive insulin pump therapy decreases the level of ROS in PBMCs. To detect the ROS levels, the DCFH-DA assay was performed using the isolated PBMCs. Prior to treatment, the ROS levels in PBMCs were similar between the two groups, and there was no significant difference. After intensive treatment, the ROS levels in the two groups were significantly decreased and the ROS levels in the experimental group were significantly lower than those in the control group (Fig. 4). The expression level of MFI pro-therapy in experimental group was significantly lower than that in control group

Short-term intensive insulin pump therapy decreases the $m R N A$ levels of $\mathrm{HO}-1$. There was no significant difference in the mRNA levels of HO-1 between the two groups prior to treatment; however, after intensive treatment, the transcription levels of HO-1 were significantly decreased in each group, and HO-1 was significantly decreased in the experimental group compared with that in the control group (Fig. 5). Compared with control group, the expression of HO-1 pro-therapy in experiment group was significantly decreased.

Short-term intensive insulin pump therapy decreases the $m R N A$ levels of Nrf2. The expression of HO-1 is regulated by the upstream transcription factor Nrf2, so the transcriptional
Table I. Short-term intensive insulin pump therapy significantly improves the function of islet $\beta$-cells in newly diagnosed type 2 diabetics.

\begin{tabular}{lll}
\hline Group/time-point & \multicolumn{1}{c}{ HOMA- $\beta$} & \multicolumn{1}{c}{ HOMA-IR } \\
\hline $\begin{array}{l}\text { Control }(\mathrm{n}=50) \\
\text { Pre-therapy }\end{array}$ & $14.73(6.53-22.67)$ & $3.45(1.87-6.03)$ \\
Pro-therapy & $46.53(30.79-62.43)^{\mathrm{a}}$ & $2.34(1.09-3.55)^{\mathrm{a}}$ \\
$\begin{array}{l}\text { Experimental } \\
\text { group (n=50) }\end{array}$ & \\
$\begin{array}{l}\text { Pre-therapy } \\
\text { Pro-therapy }\end{array}$ & $14.85(6.81-23.07)$ & $3.48(1.92-5.86)$ \\
\hline
\end{tabular}

HOMA- $\beta$, homeostasis model assessment of $\beta$-cell function; HOMA-IR, homeostasis model assessment of insulin resistance. ${ }^{a} \mathrm{P}<0.05$ vs. pre-therapy; ${ }^{\mathrm{b}} \mathrm{P}<0.05$ vs. pro-therapy in control group.

level of Nrf2 was also detected in the present study. Prior to treatment, the transcription levels of PBMCs were similar between the two groups, without exhibiting any statistically significant difference. After intensive treatment, the mRNA levels of Nrf2 in the two groups were significantly decreased. Furthermore, the mRNA levels of Nrf2 in the experimental group were significantly reduced when compared with those in the control group (Fig. 6). The expression of Nrf2 pro-therapy in experimental group was significantly downregulated in comparison with control group.

\section{Discussion}

Type 2 diabetes is a slowly progressing systemic disease with an unclear cause. It is generally thought that defects in insulin resistance and secretion have an important role in the development of type 2 diabetes. Insulin secretion defects are associated with islet $\beta$-cell dysfunction (9). Numerous factors may lead to a decrease in islet $\beta$-cell function, of which hyperglycemia is the most important and persistent cause (10). Elevated blood glucose may reduce the expression of insulin-associated genes, promote apoptosis of islet $\beta$-cells that may lead to a decrease in insulin secretion and increase blood glucose, thereby forming a vicious circle and ultimately leading to the loss of islet $\beta$-cell function (11). Studies have indicated that certain toxic effects of hyperglycemia on islet $\beta$-cells are reversible after maintaining short-term normal glucose levels (12-14). Therefore, only strict control of blood glucose is able to prevent the toxic effects of hyperglycemia on the function of islet $\beta$-cells. Short-term intensive usage of insulin may rapidly control blood glucose levels to reach the normal range. If insulin is supplemented in an approximate physiological manner, the occurrence of hyperinsulinemia may also be avoided, which may, in turn, alter the clinical course of diabetes. At the same time, lipo-toxicity caused by abnormal blood lipids also enhances the decline in the function of islet $\beta$-cells and exacerbates deficiencies in insulin action. TG may impair pro-proinsulin biosynthesis and damage the oxidation process of glucose in the islets, as well as increasing islet $\beta$-cell apoptosis (15). Insulin sensitivity decreased with increasing amounts of TG in the muscle. 
A

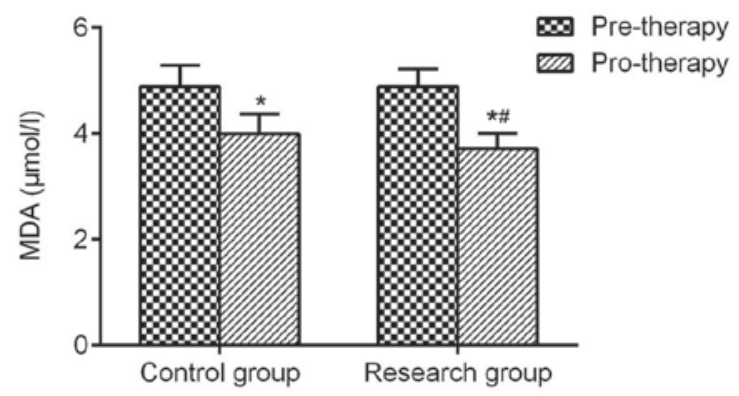

B

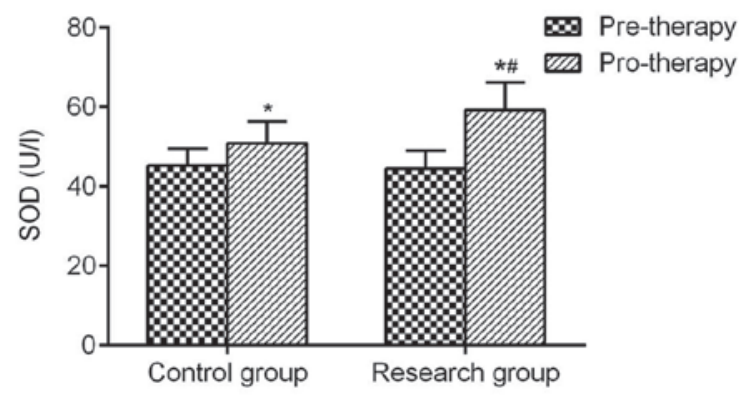

Figure 3. Serum MDA and SOD levels as redox indicators. (A) Serum MDA levels and (B) serum SOD levels pre- or pro-therapy. "P<0.05 vs. pre-therapy; ${ }^{\#} \mathrm{P}<0.05$ vs. pro-therapy in control group. MDA, malondialdehyde; SOD superoxide dismutase.

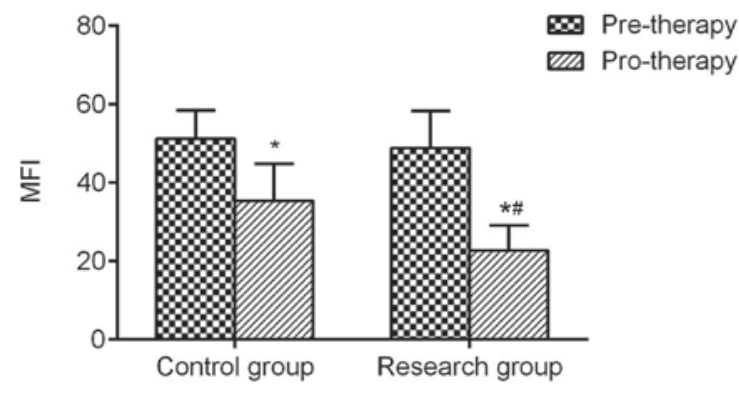

Figure 4. Serum ROS levels pre- and pro-therapy. Short-term insulin pump intensive treatment significantly decreased the ROS levels in patients with newly diagnosed type 2 diabetes. ${ }^{*} \mathrm{P}<0.05$ vs. pre-therapy; $\mathrm{P}<0.05$ vs. pro-therapy in control group. ROS, reactive oxygen species; MFI, mean fluorescence intensity.

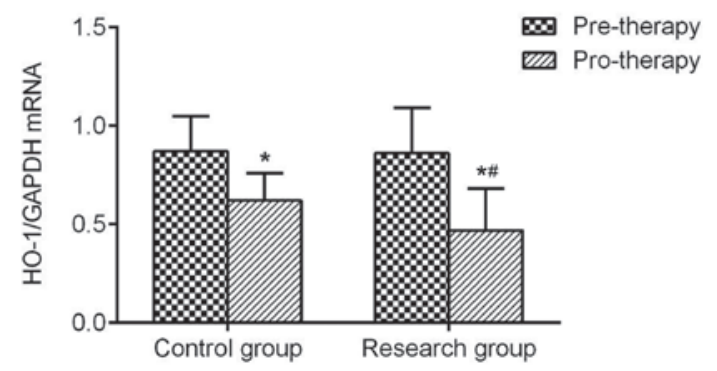

Figure 5. Transcription levels of HO-1 in peripheral blood mononuclear cells isolated from patients with newly diagnosed type 2 diabetes. mRNA levels of HO-1 pre- or pro-therapy were determined using reverse transcription-quantitative PCR. ${ }^{*} \mathrm{P}<0.05$ vs. pre-therapy; ${ }^{~} \mathrm{P}<0.05$ vs. pro-therapy in control group. HO-1, heme oxygenase 1 .

The insulin pump mimics the pulsatile release of insulin during sustained basal secretion and feeding, making insulin release more physiologically compatible. The present study indicated that the short-term intensive treatment of newly diagnosed type 2 diabetes using insulin pump rapidly and efficiently controlled the blood glucose levels, improved blood lipids and increased insulin sensitivity and islet $\beta$-cell function.

Oxidative stress is a persistent imbalance between free radical production and oxidative defense, which results in tissue damage when the body suffers from various harmful stimuli. Numerous studies have indicated that the gradual decline of islet $\beta$-cell function in type 2 diabetic patients is linked to oxidative stress caused by various factors, including

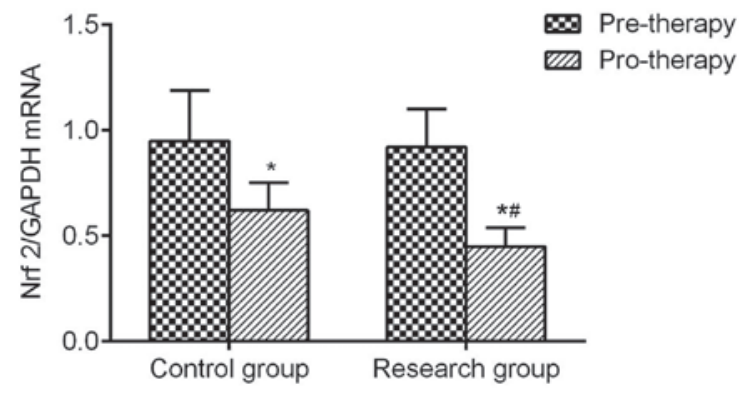

Figure 6. mRNA expression of Nrf2 in peripheral blood mononuclear cells isolated from patients with newly diagnosed type 2 diabetes. The mRNA levels of Nrf2 pre- or pro-therapy were determined using reverse transcription-quantitative PCR. " $\mathrm{P}<0.05$ vs. pre-therapy; ${ }^{\text {}} \mathrm{P}<0.05$ vs. pro-therapy in control group. Nrf2, nuclear factor erythroid 2-related factor 2.

high glucose and high fat $(16,17)$. Among them, MDA is the final breakdown product of lipid peroxidation, which reflects the lipid peroxidation rate or intensity of tissue cells (18). The concentration of MDA reflects the extent of lipid peroxidation and cell damage. In the present study, the serum level of MDA was significantly decreased in patients with newly diagnosed type 2 diabetes after short-term intensive treatment, while the level of SOD was significantly increased. On the other hand, increased ROS is also an important factor of oxidative stress. In the present study, CSII significantly reduced ROS levels in PBMCs from patients newly diagnosed with type 2 diabetes, which was consistent with the study by Zhao et al (19). However, the underlying molecular mechanisms remains to be fully elucidated.

The anti-oxidant system also has important roles in the development of diabetes and its complications (20). HOs constitute one of the important anti-oxidant systems in the body. HO-1 reduces the sensitivity of tissue and oxidative stress to reduce cell damage and apoptosis. Nrf2 is a leucine zipper protein of the 'CNC' family that binds to the DNA sequence of the anti-oxidation response element in the nucleus that regulates the expression of a series of downstream phase II detoxification enzymes and anti-oxidant genes, including HO-1. In the absence of any stimulation, Nrf2 binds to the cytosolic chaperone protein Keap1 to depress its function, which is resolved upon its release into the cytoplasm. Under oxidative stress conditions, Nrf2 is separated from Keap1 and translocates into the nucleus, where it binds to nuclear 
anti-oxidant response elements and initiates the expression of a series of phase II detoxification enzymes and anti-oxidant genes, including HO-1 (21). The present study indicated that the transcriptional level of HO-1 and its transcriptional regulatory protein Nrf2 decreased with the intensive treatment of short-term insulin pumping in patients newly diagnosed with diabetes, and their transcription level was positively paralleled with direct or indirect indicators reflecting the body's oxidative stress, which in turn maintained a balance of oxidation and anti-oxidant levels in the body. In particular, after a short-term insulin pump treatment, the redox index in diabetic patients was significantly improved.

Of note, the present study had certain limitations. Only the short-term benefits of intensive insulin treatment were assessed without long-term observations. Furthermore, the study was performed at one institution and was limited due to the small sample.

In conclusion, short-term intensive treatment with an insulin pump significantly improves blood lipids and glucose levels in patients with newly diagnosed type 2 diabetes. The function of islet $\beta$-cells was partially restored with involvement of the oxidative stress mechanism. Compared with the traditional intensive treatment with insulin injections, the effect of short-term intensive therapy with insulin pump is more effective and useful for clinical application.

\section{Acknowledgements}

Not applicable.

\section{Funding}

No funding was received.

\section{Availability of data and materials}

The datasets used and/or analyzed during the current study are available from the corresponding author on reasonable request.

\section{Authors' contributions}

HTL conceived and designed the study. YG was responsible for the collection and analysis of the data. HTL and YG interpreted the data and drafted the manuscript. All authors read and approved the final manuscript.

\section{Ethics approval and consent to participate}

The present study was approved by the Ethics Committee of Daqing Oilfield General Hospital (Daqing, China). Written informed consent was obtained from all patients.

\section{Patient consent for publication}

Not applicable.

\section{Competing interests}

The authors declare that they have no competing interests.

\section{References}

1. Urakami T, Suzuki J, Mugishima H, Amemiya S, Sugihara S, Kawamura T, Kikuchi T, Sasaki N, Matsuura N and Kitagawa T: Screening and treatment of childhood type 1 and type 2 diabetes mellitus in Japan. Pediatr Endocrinol Rev 10 (Suppl 1): S51-S61, 2012.

2. Halban PA, Polonsky KS, Bowden DW, Hawkins MA, Ling C, Mather KJ, Powers AC, Rhodes CJ, Sussel L and Weir GC: $\beta$-cell failure in type 2 diabetes: Postulated mechanisms and prospects for prevention and treatment. J Clin Endocrinol Metab 99: 1983-1992, 2014.

3. Mu J, Woods J, Zhou YP, Roy RS, Li Z, Zycband E, Feng Y, Zhu L, Li C, Howard AD, et al: Chronic inhibition of dipeptidyl peptidase- 4 with a sitagliptin analog preserves pancreatic beta-cell mass and function in a rodent model of type 2 diabetes. Diabetes 55: 1695-1704, 2006.

4. Robertson RP, Harmon J, Tran PO, Tanaka Y and Takahashi H: Glucose toxicity in beta-cells: Type 2 diabetes, good radicals gone bad, and the glutathione connection. Diabetes 52: 581-587, 2003.

5. Retnakaran R: Novel strategies for inducing glycemic remission during the honeymoon phase of type 2 diabetes. Can J Diabetes 39 (Suppl) S142-S147, 2015.

6. Marchetti P, Lupi R, Del Guerra S, Bugliani M, D'Aleo V, Occhipinti M, Boggi U, Marselli L and Masini M: Goals of treatment for type 2 diabetes beta-cell preservation for glycemic control. Diabetes Care 32 (Suppl 2): S178-S183, 2009.

7. Gabir MM, Hanson RL, Dabelea D, Imperatore G, Roumain J, Bennett PH and Knowler WC: Plasma glucose and prediction of microvascular disease and mortality: Evaluation of 1997 American Diabetes Association and 1999 World Health Organization criteria for diagnosis of diabetes. Diabetes Care 23: 1113-1118, 2000.

8. Livak KJ and Schmittgen TD: Analysis of relative gene expression data using real-time quantitative PCR and the 2(-Delta Delta C(T)) method. Methods 25: 402-408, 2001.

9. Chiu KC, Chu A, Go VL and Saad MF: Hypovitaminosis D is associated with insulin resistance and beta cell dysfunction. Am J Clin Nutr 79: 820-825, 2004.

10. Meier JJ and Bonadonna RC: Role of reduced $\beta$-cell mass versus impaired $\beta$-cell function in the pathogenesis of type 2 diabetes. Diabetes Care 36 (Suppl 2): S113-S119, 2013.

11. Rorsman P and AshcroftFM: Pancreatic $\beta$-cell electrical activity and insulin secretion: Of mice and men. Physiol Rev 98: 117-214, 2018.

12. Robertson RP: Beta-Cell deterioration during diabetes: What's in the gun? Trends Endocrinol Metab 20: 388-393, 2009.

13. White MG, Shaw JA and Taylor R: Type 2 diabetes: The pathologic basis of reversible $\beta$-Cell dysfunction. Diabetes Care 39: 2080-2088, 2016.

14. Steven $\mathrm{S}$ and Taylor R: Restoring normoglycaemia by use of a very low calorie diet in long- and short-duration type 2 diabetes. Diabet Med 32: 1149-1155, 2015.

15. Robertson RP, Harmon J, Tran PO and Poitout V: Beta-cell glucose toxicity, lipotoxicity, and chronic oxidative stress in type 2 diabetes. Diabetes 53 (Suppl 1): S119-S124, 2004.

16. Jung KY, Kim KM and Lim S: Therapeutic approaches for preserving or restoring pancreatic $\beta$-Cell function and mass. Diabetes Metab J 38: 426-436, 2014.

17. Mizukami H, Takahashi K, Inaba W, Osonoi S, Kamata K, Tsuboi K and Yagihashi S: Age-associated changes of islet endocrine cells and the effects of body mass index in Japanese. J Diabetes Investig 5: 38-47, 2014.

18. Dragun Z, Filipović Marijić V, Krasnići N, Ramani S, Valić D, Rebok K, Kostov V, Jordanova M and Erk M: Malondialdehyde concentrations in the intestine and gills of Vardar chub (Squalius vardarensis Karaman) as indicator of lipid peroxidation. Environ Sci Pollut Res Int 24: 16917-16926, 2017.

19. Zhao QB, Wang HF, Sun CF, Ma AQ and Cui CC: Effect of short-term intensive treatment with insulin pump on beta cell function and the mechanism of oxidative stress in newly diagnosed type 2 diabetic patients. Nan Fang Yi Ke Da Xue Xue Bao 27: 1878-1879, 2007 (In Chinese).

20. Bao W, Song F, Li X, Rong S, Yang W, Zhang M, Yao P, Hao L, Yang N, Hu FB and Liu L: Plasma Heme Oxygenase-1 concentration is elevated in individuals with type 2 diabetes mellitus. PLoS One 5: e12371, 2010.

21. Fukushima-Uesaka H, Saito Y, Maekawa K, Kamatani N, Kajio H, Kuzuya N, Noda M, Yasuda K and Sawada J: Genetic variations and haplotype structures of transcriptional factor Nrf2 and its cytosolic reservoir protein Keap1 in Japanese. Drug Metab Pharmacokinet 22: 212-219, 2007. 